\title{
Ectopic Expression of Hawthorn SND1 Gene in Tobacco Guofen $\operatorname{Han}^{1}$, Hongyan Dai ${ }^{2 *}$
}

\author{
College of Horticulture, Shenyang Agricultural University, Shenyang 110866, P. R. China \\ *Corresponding Author: daihy1970@163.com
}

\begin{abstract}
NAC proteins are plant-specific transcription factors (TFs) and have been shown to function in plant development processes and abiotic and/or biotic stress responses. SECONDARY WALL-ASSOCIATED NAC DOMAIN PROTEIN1 (SND1) is one type of NAC TFs, which is a key regulator in the regulation network for secondary wall synthesis. In this study, the SND1 gene, named CpSND1 because it has a conservative N-terminal DNA-binding domain with AtSND1, was isolated from hawthorn (Crataegus pinnatifida). The full-length CDS of this gene was 1,203 bp, encoding 400 amino acids. The CpSND1 gene was transferred into tobacco (Nicotiana tobacum) by the Agrobacterium-mediated transformation method, and 20 transgenic lines were obtained. Tobacco plants overexpressing CpSND1 had typical phenotypes, including inhibited growth, upward-curling leaves. Our results provided functional information of CpSND1 for future genetic engineering.
\end{abstract}

Keywords-hawthorn, transcription factor, SND1, ectopic expression.

\section{INTRODUCTION}

Secondary cell walls are largely composed of three main polymers: cellulose, hemicellulose, and lignin. These polymers are normally required to enable vascular plants not only to build strong xylem conduits for the transport of water and minerals but also to attain strong mechanical support for the plant body (Raven et al., 1999). The formation of the secondary cell wall is mainly regulated at the transcriptional level, and most of what is known about the regulation comes from the model herbaceous plant Arabidopsis thaliana. NAC (NAM-ATAF1, 2-CUC2) and MYB act as the key master switches that control secondary cell wall deposition (Taylor-Teeples et al., 2015).

NAC proteins are plant-specific transcription factors (TFs) and have been shown to function in plant development processes and abiotic and/or biotic stress responses. In Arabidopsis, there are two types NAC TFs acting as on-off switches that take part in regulating secondary wall formation in vascular cells and fibre cells. The first type of NAC TFs (VASCULARRELATED NAC-DOMAIN) VND6 and VND7 contribute to both secondary wall biosynthesis and programmed cell death of the vessels in both root and shoot tissues (Kubo et al., 2005; Yamaguchi et al., 2008). The second type of NAC TFs consists of NST3 (NAC secondary wall thickening promoting factor 3)/SND1, NST1 and NST2, which participate in thickening the secondary wall both in vascular fibre cells and secondary xylem fibre cells (Zhong and Ye, 2014). Arabidopsis NST3/SND1 is specifically expressed in vascular fibres and xylem fibres, and expressing SND1 under the control of the cauliflower mosaic virus 35S (CaMV35S) promoter can cause ectopic secondary wall deposition in non-sclerenchyma cells.

Protein binding assays have demonstrated that SND1 can bind to a DNA section with the sequence (T/A)NN(C/T)(T/C/G)TNNNNNNNA(A/C)GN(A/C/T)(A/T), named SNBE (secondary wall NAC binding element) (Zhong et al., 2008). Among the SND1-regulated transcription factors, MYB46 and MYB83 have been shown to be direct targets (Zhong et al., 2007). In particular, MYB46 and MYB86, functioning as another level of molecular switches, redundantly turn on the entire secondary wall biosynthetic programme (Zhong and Ye, 2015).

From early transcriptome data of soft-endocarp and hard-endocarp hawthorns (Dai et al., 2013), we found four NAC family transcription factors that were strongly down-regulated in the fruits of soft-endocarp hawthorn compared to the fruits of hardendocarp hawthorn. We suspected that they might participate in the biosynthesis of lignin or secondary cell walls. In this study, transgenic tobacco plants with overexpressing CpSND1 driven by the CaMV35S promoter presented growth inhibition, upward-curling leaves, which are similar to the phenotypes observed when the SND1 gene of Arabidopsis was overexpressed. Our results indicate that the $S N D 1$ function is conserved in different plants.

\section{MATERIAL AND METHOD}

\subsection{Plant materials and growth conditions}

Trees of Crataegus pinnatifida accession H8 (hard-endocarp hawthorn) were maintained in the National Hawthorn Germplasm Repository at Shenyang. The material samples were frozen in liquid $\mathrm{N}_{2}$ for RNA extraction. Tobacco seeds 
(Nictiana tabacum) were surface-sterilized and sown on MS medium with $16 \mathrm{~h}$ light $/ 8 \mathrm{~h}$ dark period at $25^{\circ} \mathrm{C}$. One month old sterile tobacco plants were used for transformation.

\subsection{Nucleic acid extraction}

Both genomic DNA and Total RNA were extracted from plant material using the modified CTAB method (Chang et al., 2007). And the RNA samples were treated with DNase I (TaKaRa, Dalian, China) for $4 \mathrm{~h}$.

\subsection{Isolation and sequence analysis of $\mathrm{CpSND1}$}

The first-strand cDNA was synthesized with PrimeScript ${ }^{\mathrm{TM}}$ 1st Strand cDNA Synthesis Kit (TaKaRa, Dalian, China). According to the assembled contig sequence of transcriptome data, specific primers were designed to obtain the full length of hawthorn SND1. The primers used to amplify SND1 were 5'-CGCCATATGTCTGATGATCAAAT-3' and 5'CGGGTACCTTACACCGACAAGTGGC-3'. The PCR cycle profile was: an initial denaturation of $95^{\circ} \mathrm{C}$ for 5 min; 34 cycles of $95^{\circ} \mathrm{C}$ for $45 \mathrm{~s}, 58^{\circ} \mathrm{C}$ for $30 \mathrm{~s}$ and $72^{\circ} \mathrm{C}$ for $1 \mathrm{~min}$; a final extension of $72^{\circ} \mathrm{C}$ for 10 min. The cDNA product was cloned into pMD18-T vector (TaKaRa, Dalian, China) and sequenced.

\subsection{Overexpression vector construction}

To overexpress the CPSND1 gene in plants, coding sequence fragment of CpSND1 was insert into plant expression vector pRI101-GFP, contain a cauliflower mosaic virus 35S (CaMV35S) promoter and the nopaline synthase terminator. The reconstructed plasmid pRI101-CpSND1 was introduced into Agrobacterium tumefaciens strain EHA105 using the freezethaw transformation method.

\subsection{Agrobacterium-mediated transformation}

To generate transgenic tobacco plants, leaf discs of tobacco were transformed by the A. tumefaciens EHA105(pRI101CpSND1) mediated transformation method described by Horsch et al., 1985. The putative transgenic tobacco plants selected with kanamycin $(30 \mathrm{mg} / \mathrm{L})$ were further identified by PCR and RT-PCR analysis and then were chosen for further experiments.

\subsection{Identification of transgenic plants by PCR}

The polymerase chain reaction (PCR) analysis was performed with isolated genomic DNA to check for the presence of the transgene in the putative transformed plants. The primers were 35S-F: 5'-ATGACGCACAATCCCACTATCCT-3' and RV: 5'-CAGGAAACAGCTATGAC-3'. The PCR cycle profile was: an initial denaturation of $95^{\circ} \mathrm{C}$ for 5 min; 34 cycles of $95^{\circ} \mathrm{C}$ for $45 \mathrm{~s}, 58^{\circ} \mathrm{C}$ for $30 \mathrm{~s}$ and $72^{\circ} \mathrm{C}$ for $1 \mathrm{~min}$; a final extension of $72^{\circ} \mathrm{C}$ for $10 \mathrm{~min}$. The amplified products were analyzed byelectrophoresis in $1.2 \%(\mathrm{w} / \mathrm{v})$ agarose gels.

\section{$2.7 \quad$ qRT-PCR}

First-strand cDNA was synthesized using the PrimeScript RT Reagent Kit with gDNA Eraser (Perfect Real Time) (TaKaRa, Dalian, China). The reverse transcription products of cDNA, diluted four times, were used as the template for quantitative PCR. Reactions were set up with SYBR Green Fast qPCR Mix (TaKaRa, Dalian, China) according to the manufacturer's instructions in a total volume of $20 \mu \mathrm{l}$ with each primer at $0.2 \mu \mathrm{M}$. The amplification programme was as follows: one cycle of $30 \mathrm{~s}$ at $95^{\circ} \mathrm{C}$ followed by 40 cycles of $5 \mathrm{~s}$ at $95^{\circ} \mathrm{C}$ and $10 \mathrm{~s}$ at $60^{\circ} \mathrm{C}$. All reactions were run in triplicate, and average values were calculated. Relative expression levels of target genes and SD values were calculated using the $2^{-\Delta \Delta C t}$ method (Livak and Schmittgen, 2001).

\section{RESULTS AND DISCUSSION}

\subsection{Isolation and sequence characteristics of $C p S N D 1$ gene}

In our early study (Dai et al., 2013), we found four NAC family transcription factors that were strongly down-regulated in the fruits of soft-endocarp hawthorn compared to the fruits of hard-endocarp hawthorn. According to the conservative NAC domain of these TFs, we aligned NAC TFs in other species, which all contained a similar NAC DNA-binding domain, by the NCBI and PLAZA web blast. Because AtSND1 was the first key switch involved in secondary wall formation, and we also found that the 8 _Unigene_BMK.37276 $[\log 2(\mathrm{~S} 7 / \mathrm{H} 8)=-6.31]$ gene was the most homologous to AtSND1, so we named the 8_Unigene_BMK.37276 gene as CpSND1. The full-length CDS of CpSND1 gene was 1,203 bp, encoding 400 amino acids (Figure1). The amino acid sequence alignment showed that CpSND1 had a highly conserved NAC DNA-binding domain (Figure 2). These bioinformatic results revealed that CpSND1 may have a similar function as AtSND1. 


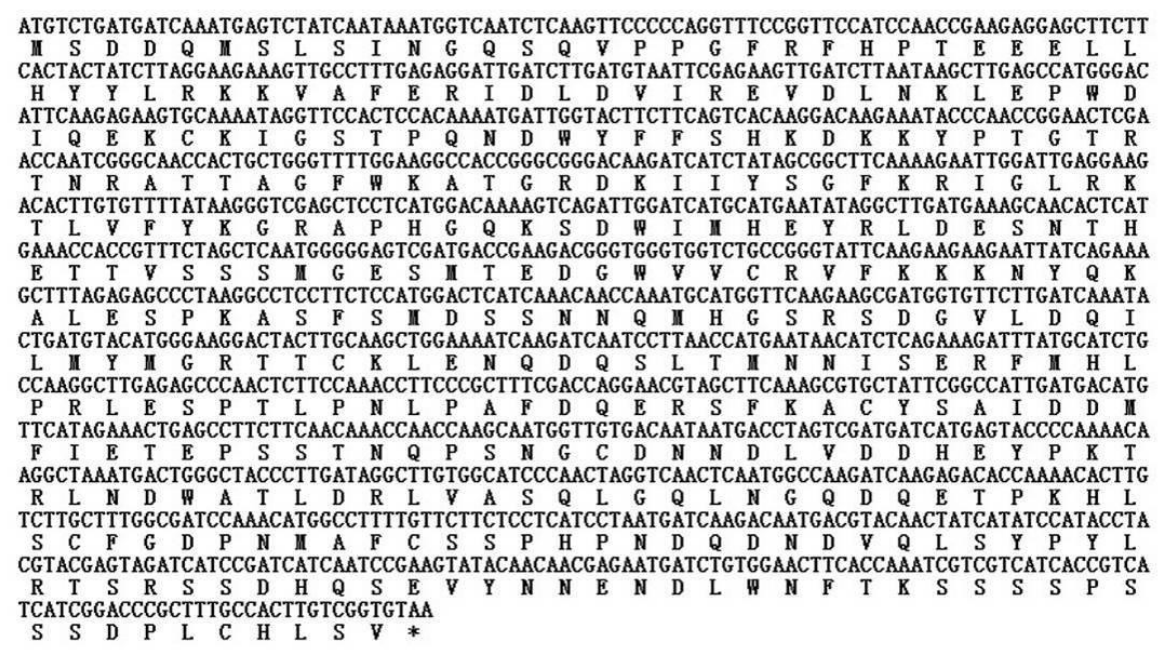

FIGURE 1 NUCLEOTIDE SEQUENCE OF CDS AND AMINO ACID OF SND1 IN HAWTHORN

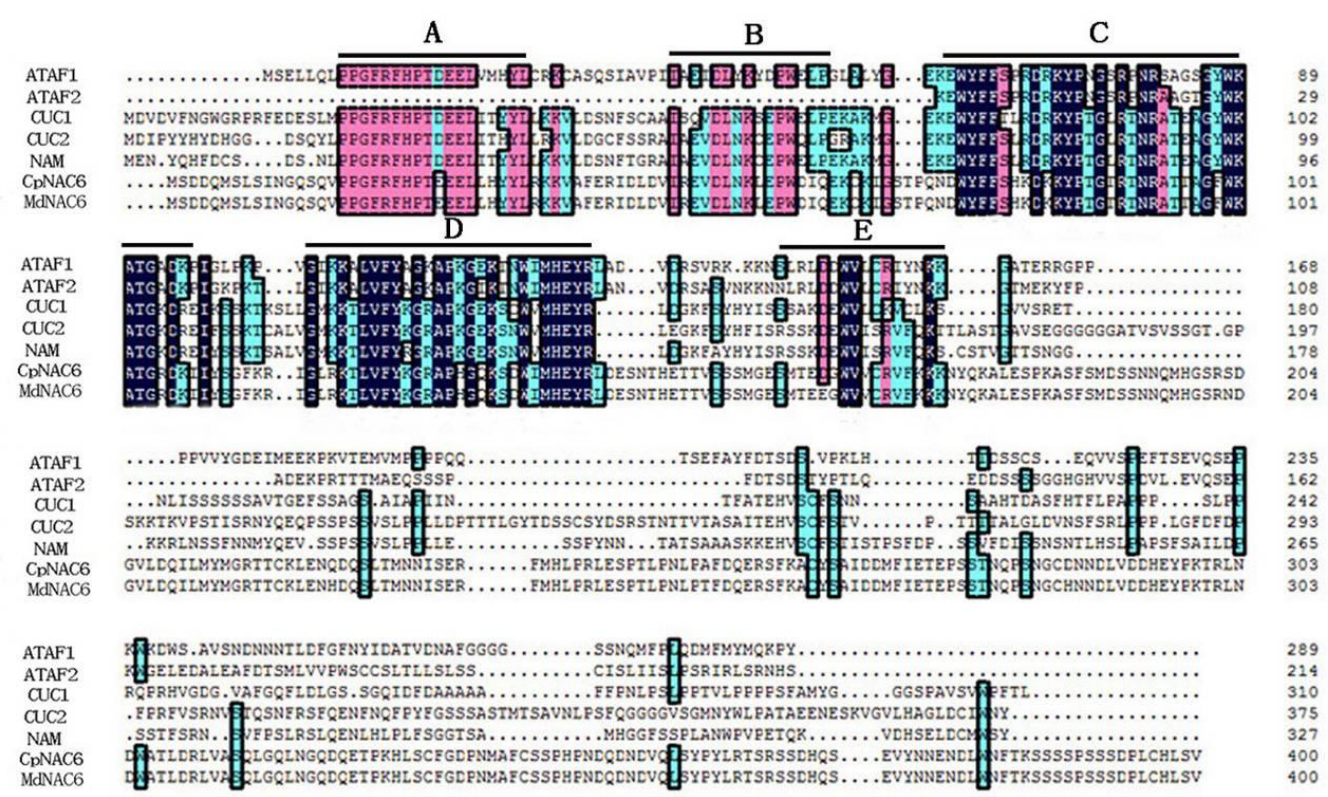

FIGURE 2 MULTIPLE SEQUENCE ALIGNMENT ANALYSIS OF HAWTHORN SND1 AND NAC DOMAIN PROTEINS FROM OTHER PLANTS

\subsection{Transformation of tobacco with $C p S N D 1$ gene}

To elucidate the biological function of the $C p S N D 1$ gene, an over-expression vector containing full CDS of $C p S N D 1$ gene was constructed and introduced into A. tumefaciens strain EHA105. Transgenic lines were obtained by Agrobacteriummediated transformation with leaf discs as explants (Figure 3).
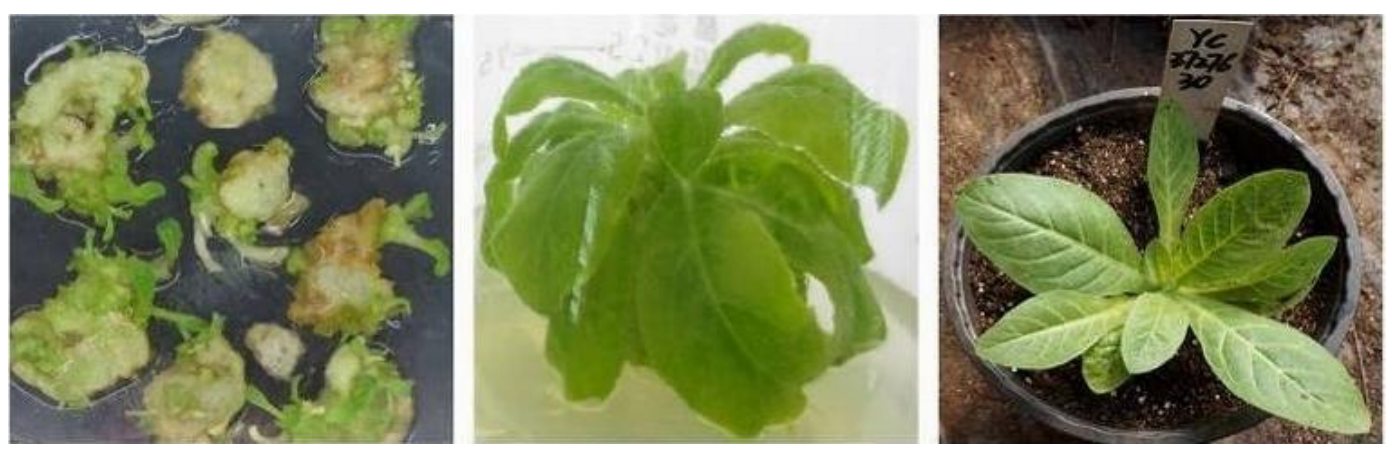

FIGURE 3: TRANSGENIC PLANTS REGENERATION FROM LEAF DISCS OF TOBACCO 
To confirm the presence of the CpSND1 gene, genomic DNAs of the kanamycin-resistant plants and non-transformed control plants were isolated. PCR analysis resulted in the expected size for the amplified fragment. No amplified product was detected in the samples containing DNA isolated from non-transformed control plants (Figure 4). Twenty transgenic lines were identified.

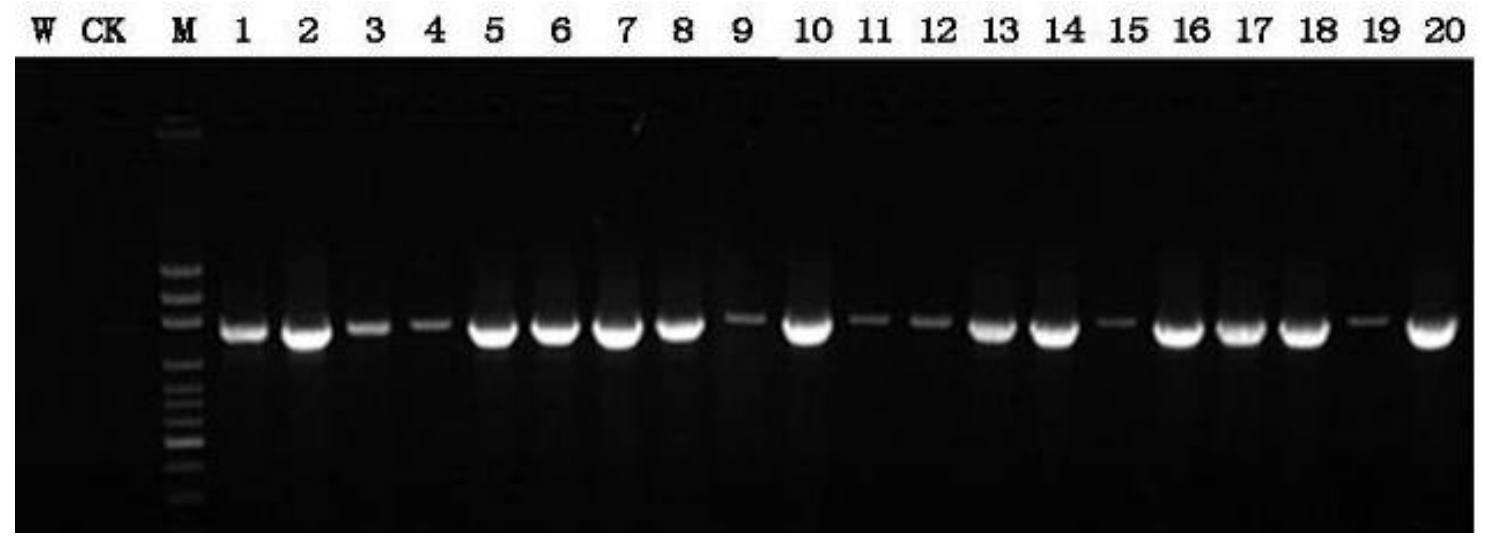

Figure 4: PCR ANALYSIS OF TRANSGENIC PLANTS OF TOBACCO. W: WATER; CK: NON-TRANSGENIC PLANT; M: MARKER, LINE 1 20: TRANSGENIC PLANTS

\subsection{Ectopic expression of CpSND1 induced curled leaves and stunted growth in tobacco}

The transgenic plants and non-transgenic plants were transplanted into pots in greenhouse at the same time. Forty days after transplantation, the phenotypes were investigated. Compared with the non-transgenic plants, the transgenic plants were smaller and exhibited stunted growth. The leaves of transgenic plants were upward-curled. These phenotypes induced by CpSND1 were similar to those induced by AtSNDI in Arabidopsis (Zhong et al., 2006). Ninety days after transplantation, the difference on phenotypes was more obvious (Figure 5).

To check the relationship of $C p S N D 1$ expression level with phenotype, the transcription level of $C p S N D 1$ gene in tobacco were analyzed by qRT-PCR. Six transgenic lines were selected, as showed in Figure 6, the expressions of $C p S N D 1$ were detected in leaves of all transgenic plants with different levels, while it could not detected in non-transgenic plants.

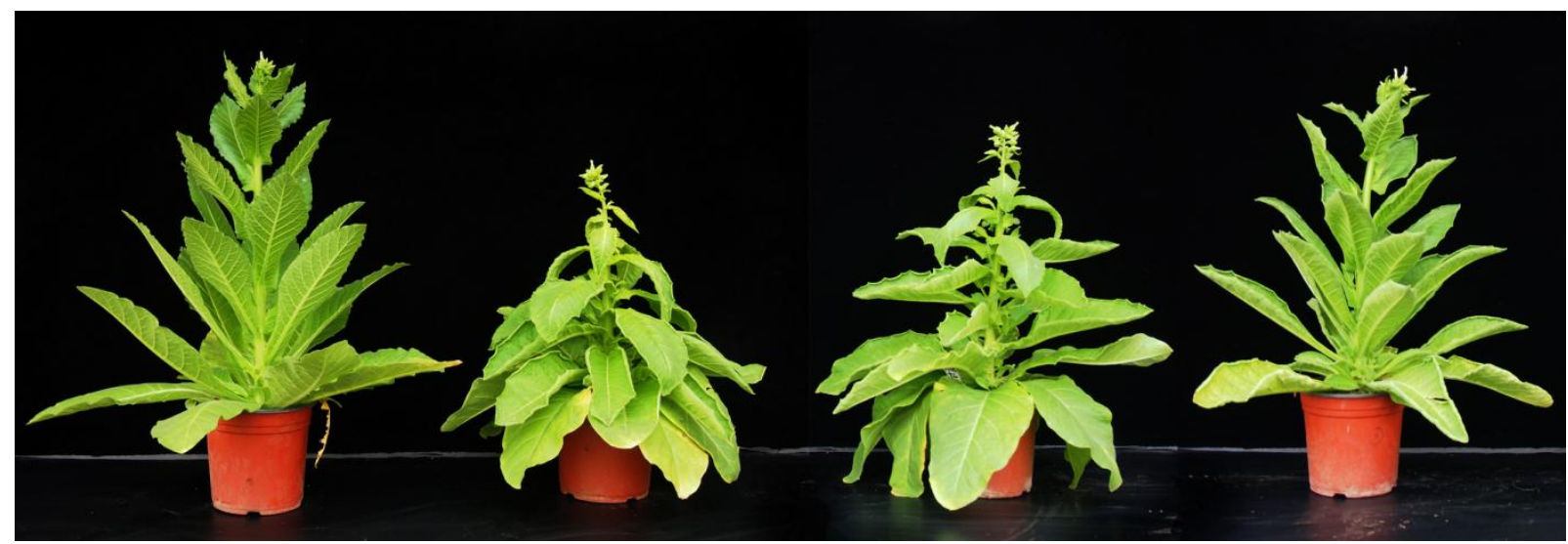

FIGURE 5 THE PHENOTYPES OF TRANSGENIC PLANTS AND NON-TRANSGENIC CONTROL (LEFT) OF TOBACCO

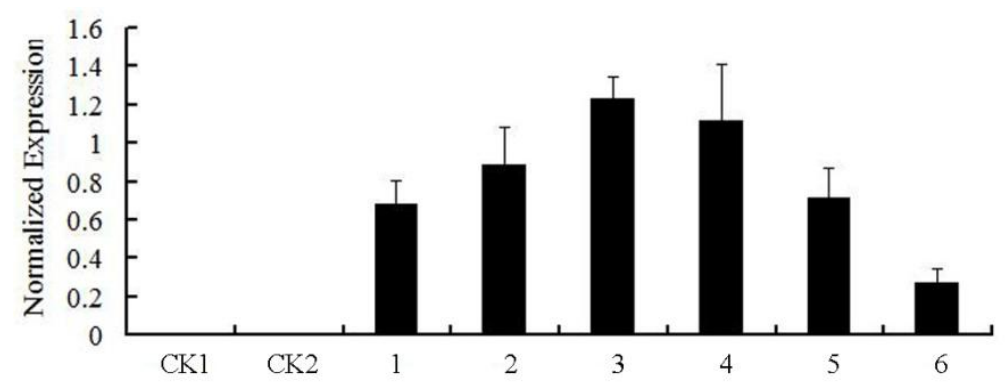

FiguRE 6 THE EXPRESSION LEVELS OF CPSND1 IN TRANSGENIC TOBACCO PLANTS. CK1 AND CK2: NON-TRANSGENIC PLANTS, LINE 1 6: TRANSGENIC PLANTS 


\section{CONCLUSION}

SND1 gene was isolated from hawthorn (Crataegus pinnatifida) and transferred into tobacco. Tobacco plants overexpressing CpSND1 gene had typical phenotypes, including inhibited growth, upward-curling leaves.

\section{ACKNOWLEDGEMENTS}

This work was supported by grants from the National Natural Science Foundation of China (31170635).

\section{REFERENCES}

[1] Chang L, Zhang Z, Yang H, Li H, Dai H. 2007. Detection of Strawberry RNA and DNA Viruses by RT-PCR using total Nucleic Acid as a Template. Journal of Phytopathology, 155, 431-436.

[2] Dai H, Han G, Yan Y, Zhang F, Liu Z, Li X, Li W, Ma Y, Li H, Liu Y, Zhang Z. 2013. Transcript assembly and quantification by RNA-Seq reveals differentially expressed genes between soft-endocarp and hard-endocarp hawthorns. PLoS ONE, 8, e72910.

[3] Horsch R B, Fry J E, Hoffmann N L, Eichholtz D, Rogers S G, Fraley R T. 1985. A simple and general method for transferring genes into plants. Science, 227, 1229-1231.

[4] Kubo M, Udagawa M, Nishikubo N, Horiguchi G, Yamaguchi M, Ito J, Mimura T, Fukuda H, Demura T. 2005. Transcription switches for protoxylem and metaxylem vessel formation. Genes \& Development, 19, 1855-1860.

[5] Livak K J, Schmittgen T D. 2001. Analysis of relative gene expression data using real-time quantitative PCR and the $2^{-\Delta \Delta C T}$ method. Methods, 25, 402-408.

[6] Raven P H, Evert R F, Eichhorn S E. 1999. Biology of Plants, 6th edn (New York: W.H. Freeman and Company).

[7] Taylor-Teeples M, Lin L, de Lucas M. 2015. An Arabidopsis gene regulatory network for secondary cell wall synthesis. Nature, 517, 571-575.

[8] Yamaguchi M, Kubo M, Fukuda H, Demura T. 2008. Vascular-related NAC-DOMAIN7 is involved in the differentiation of all types of xylem vessels in Arabidopsis roots and shoots. The Plant Journal, 55, 652-664.

[9] Zhong R, Demura T, Ye Z H. 2006. SND1, a NAC domain transcription factor, is a key regulator of secondary wall synthesis in fibers of Arabidopsis. The Plant Cell, 18, 3158-3170.

[10] Zhong R, Lee C, Zhou J, McCarthy R L, Ye Z H. 2008. A battery of transcription factors involved in the regulation of secondary cell wall biosynthesis in Arabidopsis. The Plant Cell, 20, 2763-2782.

[11] Zhong R, Richardson E A, Ye Z H. 2007. The MYB46 transcription factor is a direct target of SND1 and regulates secondary wall biosynthesis in Arabidopsis. The Plant Cell. 19, 2776-2792.

[12] Zhong R, Ye Z H. 2014. Secondary cell walls: Biosynthesis, patterned deposition and transcriptional regulation. Plant and Cell Physiology, 56, 195-214.

[13] Zhong R, Ye Z H. 2015a. The Arabidopsis NAC transcription factor NST2 functions together with SND1 and NST1 to regulate secondary wall biosynthesis in fibers of inflorescence stems. Plant Signaling Behavior, 10, e989746. 